\title{
ON THE ORIGIN OF THE 11.3 MICRON UNIDENTIFIED INFRARED EMISSION FEATURE
}

\author{
SeyedAbdolreza Sadjadi, Yong Zhang (張泳), ANd Sun KwoK (郭新) \\ Space Astronomy Laboratory, Faculty of Science, The University of Hong Kong, Pokfulam Road, Hong Kong, China; sunkwok@hku.hk \\ Received 2015 April 25; accepted 2015 May 14; published 2015 July 2
}

\begin{abstract}
The $11.3 \mu \mathrm{m}$ emission feature is a prominent member of the family of unidentified infrared emission (UIE) bands and is frequently attributed to out-of-plane bending modes of polycyclic aromatic hydrocarbon (PAH) molecules. We have performed quantum mechanical calculations of 60 neutral PAH molecules and found that it is difficult to reconcile the observed astronomical feature with any or a mix of these PAH molecules. We have further analyzed the fitting of spectra of several astronomical objects by the NASA PAH database program and found that reasonable fittings to the observed spectra are only possible by including significant contributions from oxygenand/or magnesium-containing molecules in the mix. A mix of pure PAH molecules, even including units of different sizes, geometry, and charged states, is unable to fit the astronomical spectra. Preliminary theoretical results on the vibrational spectra of simple molecules with mixed aromatic/aliphatic structures show that these structures have consistent clusters of vibrational modes and could be viable carriers of the UIE bands.
\end{abstract}

Key words: infrared: ISM - ISM: lines and bands - ISM: molecules - planetary nebulae: general

\section{INTRODUCTION}

The unidentified infrared emission (UIE) bands at 3.3, 6.2, 7.7, 8.6, 11.3, and $12.7 \mu \mathrm{m}$ are a family of infrared emission bands, which are widely observed in planetary nebulae, reflection nebulae, $\mathrm{H}$ II regions, diffuse interstellar clouds, and galaxies. In star-forming galaxies, UIE bands contribute to up to $20 \%$ of the total infrared output of the galaxies (Smith et al. 2007). The carrier of the UIE features therefore must be a major constituent of interstellar matter and their spectral characteristics can serve as potential probes for the chemical processes and physical conditions of interstellar environments (Joblin \& Tielens 2011; Peeters 2014).

The $11.3 \mu \mathrm{m}$ feature is a prominent member of the UIE family and was among the first UIE bands detected (Gillett et al. 1973). The detection of this feature in the planetary nebulae NGC $7027, \mathrm{BD}+30^{\circ} 3639$, and NGC 6572 came as a surprise as only atomic fine-structure lines were expected to be present in these objects. The strength of the $11.3 \mu \mathrm{m}$ feature was found not to be related to the excitation conditions of the nebulae and its origin was first attributed to mineral carbonates such as $\mathrm{MgCO}_{3}$ (Gillett et al. 1973). This identification was soon discarded when the expected $7.0 \mu \mathrm{m}$ feature from carbonates was not found (Russell et al. 1977b). Russell et al. (1977a) found the $11.3 \mu \mathrm{m}$ feature to be closely correlated with the $3.3 \mu \mathrm{m}$ feature, suggesting a common origin for the two features. The current accepted explanation is that these two features arise from the $\mathrm{C}-\mathrm{H}$ vibration modes of aromatic compounds (Duley \& Williams 1981). Many aromatic compounds are known by laboratory spectroscopy to show absorption bands around $3 \mu \mathrm{m}$ due to $\mathrm{C}-\mathrm{H}$ stretch and around $12 \mu \mathrm{m}$ due to $\mathrm{C}-\mathrm{H}$ out-of-plane (OOP) bending modes. The fact that the $11.3 \mu \mathrm{m}$ feature is found almost exclusively in planetary nebulae with a high $\mathrm{C}$ to $\mathrm{O}$ ratio $(>2)$, and sometimes associated with the faint $\mathrm{SiC}$ feature, suggests carbon grains as the carrier (Barlow 1983). Since then, various carbonaceous materials containing an aromatic component have been suggested as the UIE carrier. The list of candidates includes hydrogenated amorphous carbon (Duley \& Williams 1983), quenched carbon composites (Sakata et al. 1987), polycyclic aromatic hydrocarbon (PAH) molecules (Léger \& Puget 1984;
Allamandola et al. 1985; Puget \& Léger 1989), coal (Papoular et al. 1989), petroleum fractions (Cataldo \& Keheyan 2003; Cataldo et al. 2013), and mixed aromatic/aliphatic organic nanoparticles (MAONs, Kwok \& Zhang 2011, 2013). Among these proposals, the PAH hypothesis has captured the most attention and is widely believed by the astronomical community to be the carrier of the UIE features.

Assuming a PAH origin, the $11.3 \mu \mathrm{m}$ feature has been frequently used as a tool to probe the physical conditions of galaxies and active galactic nuclei (e.g., Smith et al. 2007; Galliano et al. 2008; Wu et al. 2010). The $11.3 \mu \mathrm{m}$ feature is used to trace the neutral and/or large PAHs, and the strength ratios between the $11.3 \mu \mathrm{m}$ feature and shorter wavelength (such as 6.2, 7.7, and $8.6 \mu \mathrm{m}$ ) UIE bands have been used to estimate the properties of the radiation fields. The physical validity of these studies, however, depends on a correct interpretation of the origin of the $11.3 \mu \mathrm{m}$ feature.

Recent advances in quantum-chemical methodology and computational power provide the accuracy needed to quantitatively study the UIE phenomenon. The NASA Ames PAH IR Spectroscopic Database (PAHdb; Bauschlicher et al. 2010; Boersma et al. 2014) collects theoretical infrared spectra of 700 PAH molecules. Using the density functional theory (DFT), we have calculated the IR spectra of a series of molecules with mixed aliphatic-aromatic structures (Sadjadi et al. 2015). In this study, we reexamine the $11.3 \mu \mathrm{m}$ feature utilizing the PAHdb data and new quantum chemistry calculations.

\section{OBSERVATIONS OF THE $11.3 \mu \mathrm{m}$ FEATURE IN DIFFERENT ASTRONOMICAL SOURCES}

The observed peak position of the $11.3 \mu \mathrm{m}$ feature in astronomical sources is well defined and does not vary much in wavelength. The $11.3 \mu \mathrm{m}$ feature is also detected in absorption (Bregman et al. 2000), and its wavelengths and profiles closely resemble those seen in emission. The $11.3 \mu \mathrm{m}$ feature has a distinctive asymmetric profile, having a steep decline in the short-wavelength side and a gradual extended wing in the longwavelength side (van Diedenhoven et al. 2004). Such asymmetric profiles are difficult to explain by gas-phase molecular emissions. Explanations offered include having 
PAH molecules of different mass ranges, with the high-mass PAHs responsible for the short-wavelength side and low-mass PAHs for the long-wavelength side (Candian \& Sarre 2015). Furthermore, the peak positions of the $\mathrm{C}-\mathrm{H}$ OOP bending modes of PAH molecules can be quite different due to mode coupling, molecular structure and charge states of the molecules (Hony et al. 2001). Because of the large wavelength variations of the OOP modes of PAH molecules, it is difficult to assign or match the observed astronomical feature to specific PAH molecules. One suggestion of a possible solution to this problem is to incorporate internal hydrogen in carbonaceous microparticles (Balm \& Kroto 1990). Ring deformation vibrational mode of small carbonaceous molecules such as ethylene oxide $\left(c-\mathrm{C}_{2} \mathrm{H}_{4} \mathrm{O}\right)$ has also been proposed to explain the narrow $11.3 \mu \mathrm{m}$ feature (Bernstein \& Lynch 2009).

Like the other UIE bands, the $11.3 \mu \mathrm{m}$ feature is not seen in AGB stars but only emerges during the post-AGB phase of evolution. Goebel et al. (1995) did not detect this feature in 718 carbon stars, except a feature at $11.9 \mu \mathrm{m}$ in several sources. The situation is further complicated by the blending of a $\mathrm{SiC}$ feature ("class $\delta$ " spectra according to Matsuura et al. 2014). A sample study of Herbig Ae/Be stars shows that the central wavelength of the $11.3 \mu \mathrm{m}$ feature decreases with increasing effective temperature of the central stars (Keller et al. 2008), suggesting that the chemical structure of its carrier is being processed by stellar radiation. In the spectral classification scheme of Peeters et al. (2002), the $11.3 \mu \mathrm{m}$ feature occurs at a longer wavelength in Class C sources in comparison to those in class A and B objects. Since Class C sources usually show aliphatic features (e.g., at $3.4 \mu \mathrm{m}$ ), it is thought that the peak position of the $11.3 \mu \mathrm{m}$ feature may reflect the aliphatic/aromatic ratio.

The $11.3 \mu \mathrm{m}$ feature is not an isolated spectral feature. In the spectra of proto-planetary nebulae, weaker emission features at $12.1,12.4$, and $13.3 \mu \mathrm{m}$ are also seen to accompany the $11.3 \mu \mathrm{m}$ feature (Kwok et al. 1999). It is known from laboratory studies of substituted aromatic molecules that the frequencies of the OOP bending mode correlates with the number of adjacent $\mathrm{H}$ atoms on each ring (Bellamy 1958). This empirical rule has been translated to the correlation between OOP vibrational frequencies and the number of exposed hydrogens in PAH molecules (Hudgins \& Allamandola 1999). In the simplest PAH molecule benzene, all corners are exposed and the molecule has six exposed $\mathrm{H}$ atoms. As the number of fused rings increases in two dimensions in a plane (growth of graphene flakes), the number of exposed $\mathrm{H}$ atoms on each benzene ring varies. In general, the more compact a $\mathrm{PAH}$ molecule, the fewer number of exposed $\mathrm{H}$ sites on each benzene ring of a PAH molecule. The hydrogens on these benzene units are thus labeled as solo, duo, trio, quartet, quintet, and sextet corresponding to 1, 2, 3, 4, 5, or 6 exposed $\mathrm{H}$ corners. It has been suggested that the wavelength of the mode increases monotonically from solo to sextet (Hudgins \& Allamandola 1999). The observed emission features at 11.3, $12.1,12.4$, and $13.3 \mu \mathrm{m}$ may therefore correspond to the OOP modes of solo, duo, trio, and quartet systems. We should note that these OOP bending modes are also seen in more complex amorphous hydrocarbons with mixed aromatic/aliphatic structures (Herlin et al. 1998). Absorption features at 11.36, 11.92, 12.27 , and $13.27 \mu \mathrm{m}$ in the laboratory sample are identified as solo, duo, trio, and quartet OOP modes, respectively.

In addition to the narrow features mentioned above, astronomical spectra in this spectral region also show a broad emission plateau extending from 11 to $13 \mu \mathrm{m}$. This plateau feature has been suggested to be due to OOP bending modes of a collection of PAH molecules with non-isolated $\mathrm{H}$ atoms (Cohen et al. 1985). From laboratory studies of amorphous carbon particles, Borghesi et al. (1987) suggested that the $11.3 \mu \mathrm{m}$ feature is due to combined contributions of both OOP aromatic $\mathrm{CH}$ bending and infrared lattice modes. Through a spatial and spectral study of the Orion bar, Bregman et al. (1989) concluded that the narrow $11.3 \mu \mathrm{m}$ feature and the $11-13 \mu \mathrm{m}$ plateau emission are produced by separate components: free-flying PAHs and amorphous carbon particles or PAH clusters. Highly hydrogenated PAH chrysene has also been proposed as the possible cause of the $11-13 \mu \mathrm{m}$ broad emission complex in F- and G-type stars (Justtanont et al. 1996). From a study of the broad emission plateau features observed in proto-planetary nebulae, Kwok et al. (2001) suggest that the 8 and $12 \mu \mathrm{m}$ plateau features are due to superpositions of in-plane and OOP bending modes of aliphatic side groups attached to aromatic rings. Quantum-chemical calculations indicate that the addition of aliphatic side groups indeed is able to produce a plateau around $12 \mu \mathrm{m}$ (Sadjadi et al. 2015).

In the next section, we will perform theoretical quantum chemistry calculations to determine the OOP bending mode frequencies of PAH molecules in the 11-12 $\mu \mathrm{m}$ region and explore the relationship between these modes and the astronomical $11.3 \mu \mathrm{m}$ feature.

\section{OOP C-H BENDING MODES OF PAH MOLECULES}

As the result of advances in quantum chemistry techniques, the vibrational spectrum of simple molecules such as PAH can be calculated very accurately. In order to explore the OOP bending modes of PAH molecules, we have performed quantum chemistry calculations on a large group of $\mathrm{PAH}$ molecules. A set of 60 neutral PAH molecules are selected from the PAH online databases of Boersma et al. (2014) and Malloci et al. (2007). The names and chemical formulae of these molecules are listed in Table 1 and their chemical strutures shown in Figure 1. We first use the B3LYP (Becke 1993a; Hertwig \& Koch 1997) and BHandHLYP hybrid functionals (Becke 1993b) in combination with polarization consistent basis set PC1 (Jensen 2001, 2002) to obtain the equilibrium geometries and the fundamental vibrational harmonic frequencies of the molecules. The calculations were based on DFT using the Gaussian 09, Revision C.01 software package (Frisch et al. 2009) running on the HKU grid-point supercomputer facility. The B3LYP calculations were done using PQS ${ }^{1}$ running on the QS128-2300C-OA16 QuantumCubeTM machine. The double scaling factors scheme of (Laury et al. 2012) were then applied to the DFT vibrational frequencies. In this scheme the vibrational frequencies $>1000$ and $<1000 \mathrm{~cm}^{-1}$ are scaled by 0.9311 and 0.9352 for BHandHLYP hybrid functionals and 0.9654 and 0.9808 for B3LYP, respectively. The astronomical infrared emission spectra are then simulated by applying the Drude model at $T=500 \mathrm{~K}$ to these scaled vibrational lines. The good accuracy and reliability of such DFT/Drude modeling in simulation of

\footnotetext{
1 PQS version 4.0, Parallel Quantum Solutions, 2013 Green Acres Road, Fayetteville, Arkansas 72703 URL: http://www.pqs-chem.com Email: sales@pqs-chem.com: Parallel Quantum Solutions.
} 
Table 1

Our Sample of PAH Molecules and the Peripheral H Sites in Each Molecule

\begin{tabular}{|c|c|c|c|c|c|c|c|c|}
\hline \multirow[t]{2}{*}{ No. } & \multirow[t]{2}{*}{ Molecule } & \multirow[t]{2}{*}{ Formula } & \multicolumn{6}{|c|}{ Percentages } \\
\hline & & & Solo & Duo & Trio & Quartet & Quintet & $\overline{\text { Sextet }}$ \\
\hline 1 & Benzene & $\mathrm{C}_{6} \mathrm{H}_{6}$ & 0 & 0 & 0 & 0 & 0 & 100 \\
\hline 2 & Naphthalene & $\mathrm{C}_{10} \mathrm{H}_{8}$ & 0 & 0 & 0 & 100 & 0 & 0 \\
\hline 3 & Anthracene & $\mathrm{C}_{14} \mathrm{H}_{10}$ & 20 & 0 & 0 & 80 & 0 & 0 \\
\hline 4 & phenanthrene & $\mathrm{C}_{14} \mathrm{H}_{10}$ & 0 & 20 & 0 & 80 & 0 & 0 \\
\hline 5 & Pyrene & $\mathrm{C}_{16} \mathrm{H}_{10}$ & 0 & 40 & 60 & 0 & 0 & 0 \\
\hline 6 & Tertracene & $\mathrm{C}_{18} \mathrm{H}_{12}$ & 33 & 0 & 0 & 67 & 0 & 0 \\
\hline 7 & Chrysene & $\mathrm{C}_{18} \mathrm{H}_{12}$ & 0 & 33 & 0 & 67 & 0 & 0 \\
\hline 8 & Triphenylene & $\mathrm{C}_{18} \mathrm{H}_{12}$ & 0 & 0 & 0 & 100 & 0 & 0 \\
\hline 9 & Benzo[a]anthracene & $\mathrm{C}_{18} \mathrm{H}_{12}$ & 17 & 17 & 0 & 66 & 0 & 0 \\
\hline 10 & Perylene & $\mathrm{C}_{20} \mathrm{H}_{12}$ & 0 & 0 & 100 & 0 & 0 & 0 \\
\hline 11 & Benzo[a]pyrene & $\mathrm{C}_{20} \mathrm{H}_{12}$ & 9 & 33 & 25 & 33 & 0 & 0 \\
\hline 12 & Benzo[e]pyrene & $\mathrm{C}_{20} \mathrm{H}_{12}$ & 0 & 17 & 50 & 33 & 0 & 0 \\
\hline 13 & Anthanthrene & $\mathrm{C}_{22} \mathrm{H}_{12}$ & 17 & 33 & 50 & 0 & 0 & 0 \\
\hline 14 & Benzo[ghi]perylene & $\mathrm{C}_{22} \mathrm{H}_{12}$ & 0 & 50 & 50 & 0 & 0 & 0 \\
\hline 15 & Pentacene & $\mathrm{C}_{22} \mathrm{H}_{14}$ & 43 & 0 & 0 & 57 & 0 & 0 \\
\hline 16 & Coronene & $\mathrm{C}_{24} \mathrm{H}_{12}$ & 0 & 100 & 0 & 0 & 0 & 0 \\
\hline 17 & Dibenzo[b,def] chrysene & $\mathrm{C}_{24} \mathrm{H}_{14}$ & 14 & 29 & 0 & 57 & 0 & 0 \\
\hline 18 & Dibenzo[cd,lm]perylene & $\mathrm{C}_{26} \mathrm{H}_{14}$ & 0 & 57 & 43 & 0 & 0 & 0 \\
\hline 19 & Hexacene & $\mathrm{C}_{26} \mathrm{H}_{16}$ & 50 & 0 & 0 & 50 & 0 & 0 \\
\hline 20 & Bisanthene & $\mathrm{C}_{28} \mathrm{H}_{14}$ & 14 & 0 & 86 & 0 & 0 & 0 \\
\hline 21 & Benzo[a]coronene & $\mathrm{C}_{28} \mathrm{H}_{14}$ & 0 & 71 & 0 & 29 & 0 & 0 \\
\hline 22 & Dibenzo[fg,st]pentacene & $\mathrm{C}_{28} \mathrm{H}_{16}$ & 13 & 0 & 37 & 50 & 0 & 0 \\
\hline 23 & Dibenzo[bc,kl]coronene & $\mathrm{C}_{30} \mathrm{H}_{14}$ & 29 & 29 & 42 & 0 & 0 & 0 \\
\hline 24 & Dibenzo[bc,ef]coronene & $\mathrm{C}_{30} \mathrm{H}_{14}$ & 14 & 43 & 43 & 0 & 0 & 0 \\
\hline 25 & Naphtho $[8,1,2 \mathrm{abc}]$ coronene & $\mathrm{C}_{30} \mathrm{H}_{14}$ & 7 & 71 & 22 & 0 & 0 & 0 \\
\hline 26 & Terrylene & $\mathrm{C}_{30} \mathrm{H}_{16}$ & 0 & 25 & 75 & 0 & 0 & 0 \\
\hline 27 & Ovalene & $\mathrm{C}_{32} \mathrm{H}_{14}$ & 14 & 86 & 0 & 0 & 0 & 0 \\
\hline 28 & Tetrabenzocoronene & $\mathrm{C}_{36} \mathrm{H}_{16}$ & 25 & 0 & 75 & 0 & 0 & 0 \\
\hline 29 & Benz[a]ovalene & $\mathrm{C}_{36} \mathrm{H}_{16}$ & 13 & 62 & 0 & 25 & 0 & 0 \\
\hline 30 & Dibenzo[hi,yz]heptacene & $\mathrm{C}_{36} \mathrm{H}_{20}$ & 30 & 0 & 30 & 40 & 0 & 0 \\
\hline 31 & Circumbiphenyl & $\mathrm{C}_{38} \mathrm{H}_{16}$ & 0 & 100 & 0 & 0 & 0 & 0 \\
\hline 32 & Naphth $[8,2,1$, abc $]$ ovalene & $\mathrm{C}_{38} \mathrm{H}_{16}$ & 19 & 62 & 19 & 0 & 0 & 0 \\
\hline 33 & Circumanthracene & $\mathrm{C}_{40} \mathrm{H}_{16}$ & 25 & 75 & 0 & 0 & 0 & 0 \\
\hline 34 & Phenanthro[ $3,4,5,6$ vuabc]ovalene & $\mathrm{C}_{40} \mathrm{H}_{16}$ & 13 & 87 & 0 & 0 & 0 & 0 \\
\hline 35 & Quaterrylene & $\mathrm{C}_{40} \mathrm{H}_{20}$ & 0 & 40 & 60 & 0 & 0 & 0 \\
\hline 36 & Dibenz $[\mathrm{jk}, \mathrm{a} 1 \mathrm{~b} 1]$ octacene & $\mathrm{C}_{40} \mathrm{H}_{22}$ & 36 & 0 & 28 & 36 & 0 & 0 \\
\hline 37 & Circumpyrene & $\mathrm{C}_{42} \mathrm{H}_{16}$ & 25 & 75 & 0 & 0 & 0 & 0 \\
\hline 38 & Hexabenzocoronene & $\mathrm{C}_{42} \mathrm{H}_{18}$ & 0 & 0 & 100 & 0 & 0 & 0 \\
\hline 39 & Honeycomb $15^{\mathrm{a}}$ & $\mathrm{C}_{46} \mathrm{H}_{18}$ & 22 & 56 & 0 & 22 & 0 & 0 \\
\hline 40 & Honeycomb16 & $\mathrm{C}_{48} \mathrm{H}_{18}$ & 17 & 66 & 17 & 0 & 0 & 0 \\
\hline 41 & Dicoronylene & $\mathrm{C}_{48} \mathrm{H}_{20}$ & 20 & 80 & 0 & 0 & 0 & 0 \\
\hline 42 & Honeycomb17 & $\mathrm{C}_{50} \mathrm{H}_{18}$ & 28 & 55 & 17 & 0 & 0 & 0 \\
\hline 43 & Pentarylene & $\mathrm{C}_{50} \mathrm{H}_{24}$ & 0 & 50 & 50 & 0 & 0 & 0 \\
\hline 44 & Honeycomb18 & $\mathrm{C}_{52} \mathrm{H}_{18}$ & 33 & 67 & 0 & 0 & 0 & 0 \\
\hline 45 & Circumcoronene & $\mathrm{C}_{54} \mathrm{H}_{18}$ & 33 & 67 & 0 & 0 & 0 & 0 \\
\hline 46 & Honeycomb19 & $\mathrm{C}_{56} \mathrm{H}_{20}$ & 30 & 50 & 0 & 20 & 0 & 0 \\
\hline 47 & Honeycomb20 & $\mathrm{C}_{58} \mathrm{H}_{20}$ & 35 & 50 & 15 & 0 & 0 & 0 \\
\hline 48 & Honeycomb21 & $\mathrm{C}_{62} \mathrm{H}_{22}$ & 32 & 36 & 14 & 18 & 0 & 0 \\
\hline 49 & Honeycomb22 & $\mathrm{C}_{64} \mathrm{H}_{22}$ & 36 & 36 & 28 & 0 & 0 & 0 \\
\hline 50 & Circumovalene & $\mathrm{C}_{66} \mathrm{H}_{20}$ & 40 & 60 & 0 & 0 & 0 & 0 \\
\hline 51 & Honeycomb23 & $\mathrm{C}_{66} \mathrm{H}_{22}$ & 36 & 46 & 0 & 18 & 0 & 0 \\
\hline 52 & Honeycomb24 & $\mathrm{C}_{70} \mathrm{H}_{24}$ & 25 & 33 & 25 & 17 & 0 & 0 \\
\hline 53 & Honeycomb25 & $\mathrm{C}_{72} \mathrm{H}_{24}$ & 21 & 50 & 12 & 17 & 0 & 0 \\
\hline 54 & Honeycomb26 & $\mathrm{C}_{74} \mathrm{H}_{24}$ & 21 & 50 & 12 & 17 & 0 & 0 \\
\hline 55 & Honeycomb27 & $\mathrm{C}_{78} \mathrm{H}_{26}$ & 19 & 31 & 35 & 15 & 0 & 0 \\
\hline 56 & Honeycomb28 & $\mathrm{C}_{80} \mathrm{H}_{26}$ & 19 & 31 & 35 & 15 & 0 & 0 \\
\hline 57 & Honeycomb29 & $\mathrm{C}_{82} \mathrm{H}_{26}$ & 19 & 31 & 35 & 15 & 0 & 0 \\
\hline 58 & Honeycomb30 & $\mathrm{C}_{84} \mathrm{H}_{26}$ & 15 & 47 & 23 & 15 & 0 & 0 \\
\hline 59 & Honeycomb43 & $\mathrm{C}_{120} \mathrm{H}_{36}$ & 67 & 33 & 0 & 0 & 0 & 0 \\
\hline 60 & Kekulene & $\mathrm{C}_{48} \mathrm{H}_{24}$ & 50 & 50 & 0 & 0 & 0 & 0 \\
\hline
\end{tabular}

Note.

"The number "xx" in the label "Honeycombxx" denotes the number of fused benzene rings in the molecular structure of the PAH molecule. 


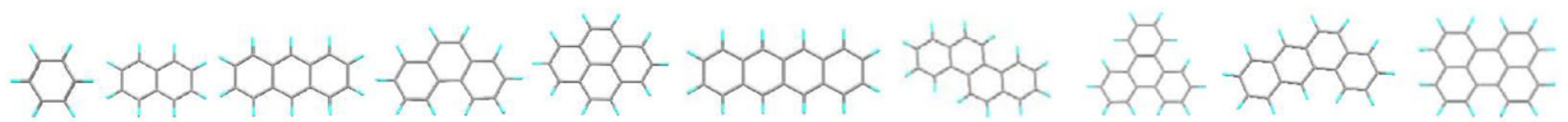

(2)

(4)

(5)

(6)

(7)

(8)

(9)

(10)

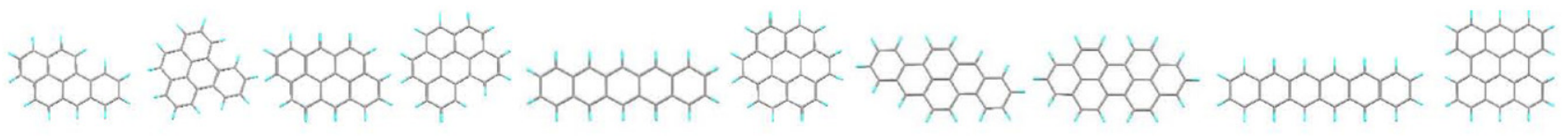

(11)

(12)

(13)

(14)

(15)

(16)

(17)

(18)

(19)

(20)

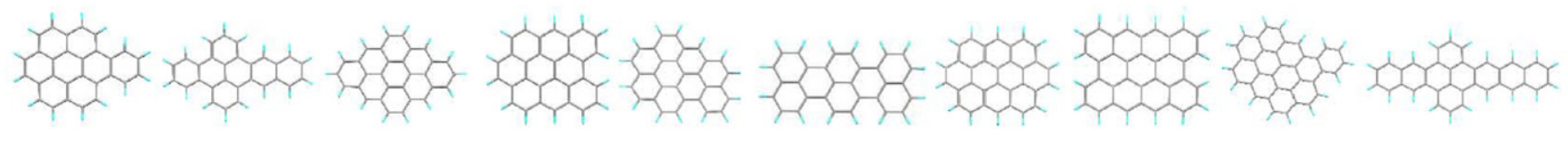

(21)

(22)

(23)

(24)

(25)

(26)

(27)

(28)

(29)

(30)
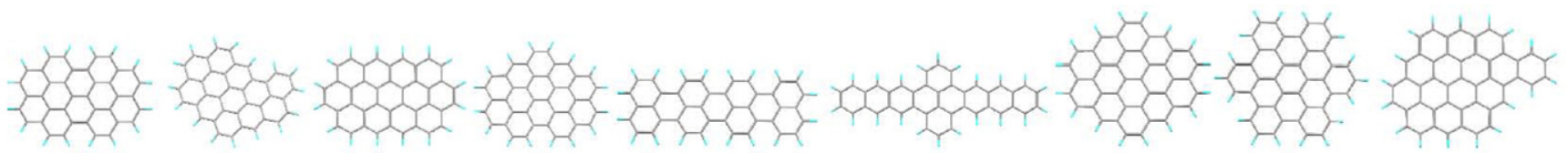

(31)

(32)

(33)

(34)

(35)

(36)

(37)

(38)

(39)

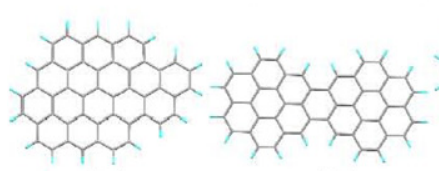

(40)
(41)

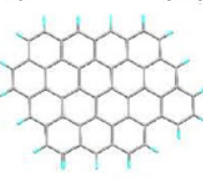

(42)

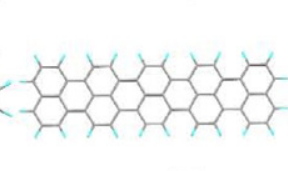

(43)

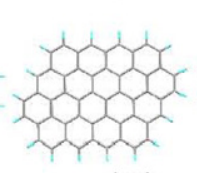

(44)

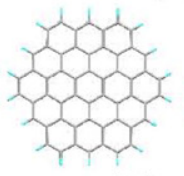

(45)

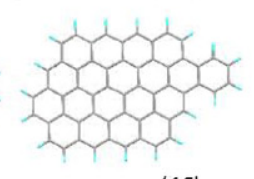

(46)

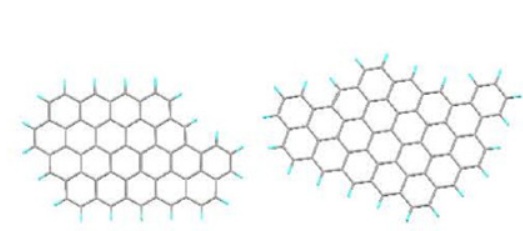

(47)

(48)

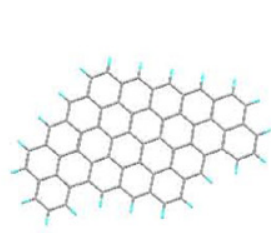

(49)

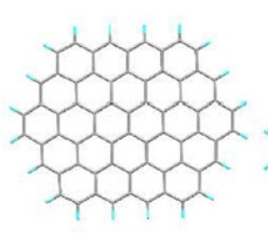

(50)

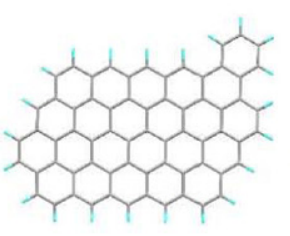

(51)

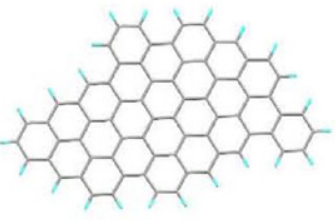

(52)

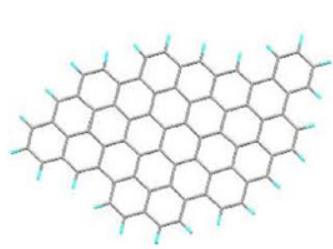

(53)

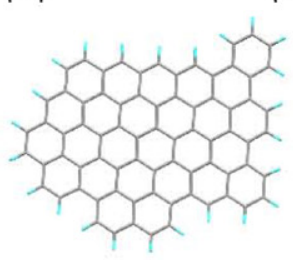

(54)

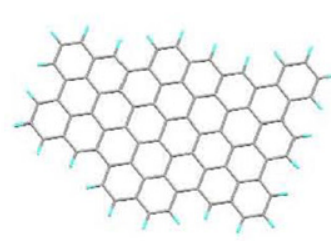

(55)

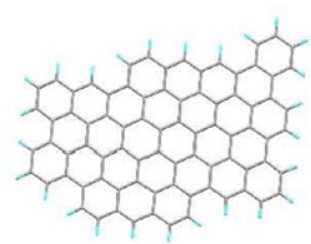

(56)

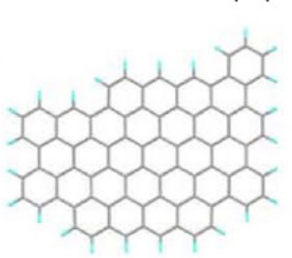

(57)

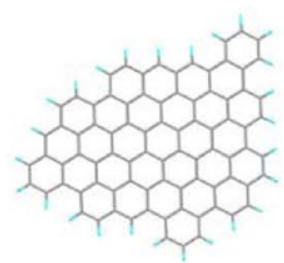

(58)

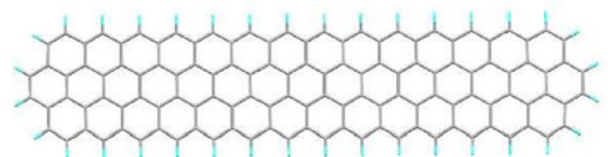

(59)

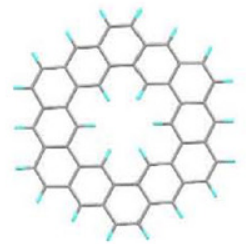

(60)

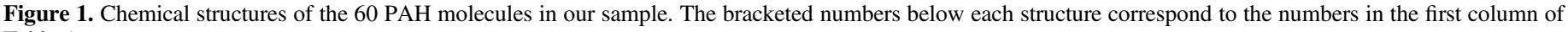
Table 1.

astronomical IR emission bands was demonstrated in our previous study (Sadjadi et al. 2015).

All geometries have been optimized under the default criteria of the cited ab intio quantum chemistry packages. The optimized geometries are all characterized as local minima, established by the positive values of all frequencies and their associated eigenvalues of the second derivative matrix. Visualizing and manipulating the results of vibrational normal mode analysis were performed by utilizing the Chemcraft program. The Drude model is applied followed by a decomposition of normal mode analysis (Sadjadi et al. 2015). 


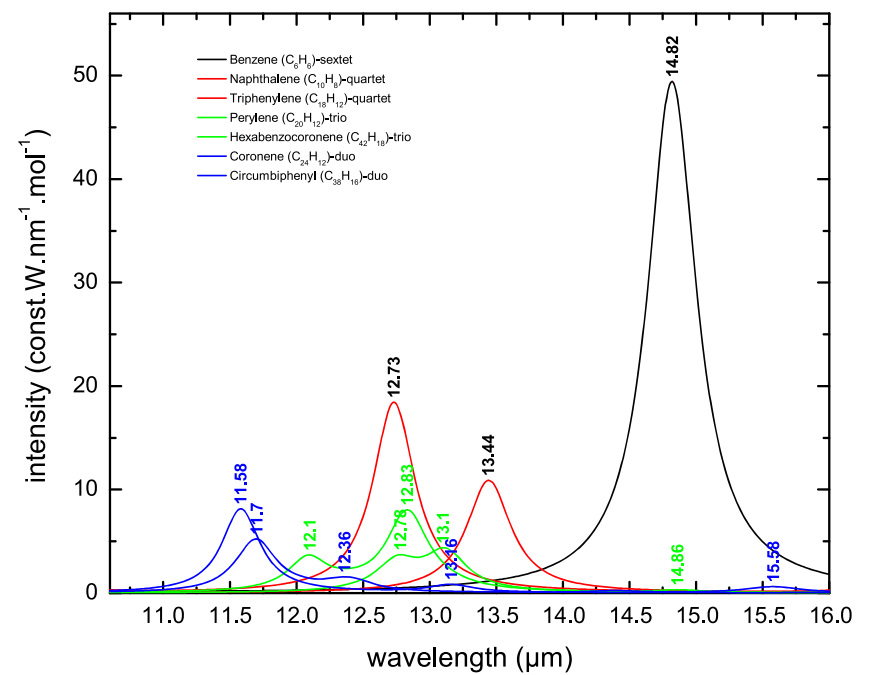

Figure 2. Wavelengths of pure OOP bending modes of seven simple PAH molecules with uniform edges. Molecules with the same number of exposed edges are plotted in the same color (duo in red, trio in green, quartet in blue). The benzene molecule (pure sextet, in black) is also plotted for comparison. The peak wavelengths of each band are also labeled on the curves.

\subsection{Dependence of the OOP Frequencies on the Number of Exposed H Sites}

In order to study the changes in frequency of the OOP bending modes of molecules with different numbers of exposed $\mathrm{H}$ sites, we have selected seven compact PAH molecules that have uniform edges, i.e., each of the molecules can be labeled as having only solo, duo, trio, or quartet sites. Because of this uniformity, these molecules are expected to have less complicated vibrational modes in the range of $10.8-15 \mu \mathrm{m}$ (the accepted region of spectra for OOP vibrations). Figure 2 shows the wavelengths of the pure OOP bending modes of these seven molecules. We can see that while the duo molecules (coronene and circumbiphenyl) have shorter wavelength peaks than the trio (perylene and hexabenzocoronene) and quartet (naphthalene and triphenylene) molecules, the latter two groups are less well separated. While both naphthalene and triphenylene are classified as quartet sites, they show the OOP bands at 12.73 and $13.44 \mu \mathrm{m}$, respectively. Perylene, which is classified as a trio site, shows the band at $12.83 \mu \mathrm{m}$, close to that of naphthalene.

The reason for this inconsistency can be explored by looking at the triphenylene (D3d) and perylene (D2h) optimized geometry and molecular symmetry. The Hs on each rings of these molecules are not equivalent as it is implied under the solo, duo, trio, quartet classification scheme. The $\mathrm{Hs}$ on triphenylene rings are grouped into two symmetry equivalent groups, i.e., one pair of duo $\mathrm{H}$ and two para solo Hs. In the same line of reasoning, the $\mathrm{Hs}$ on each of the rings on perylene are grouped into three different $\mathrm{H}$ atoms that are not symmetrically equivalent to each other, although they are classified as trio.

For non-compact PAH molecules, there will be mixed solo, duo, trio, and quartet sites. Our quantitative normal mode displacement vector analysis yields the number of $\mathrm{H}$ atoms with major contributions in specific OOP vibrational mode. From these groups of $\mathrm{H}$ atoms the number of solo, duo, trio, and quartet $\mathrm{H}$ atoms are counted and converted into percentage values for the contribution of each edge-class in that OOP

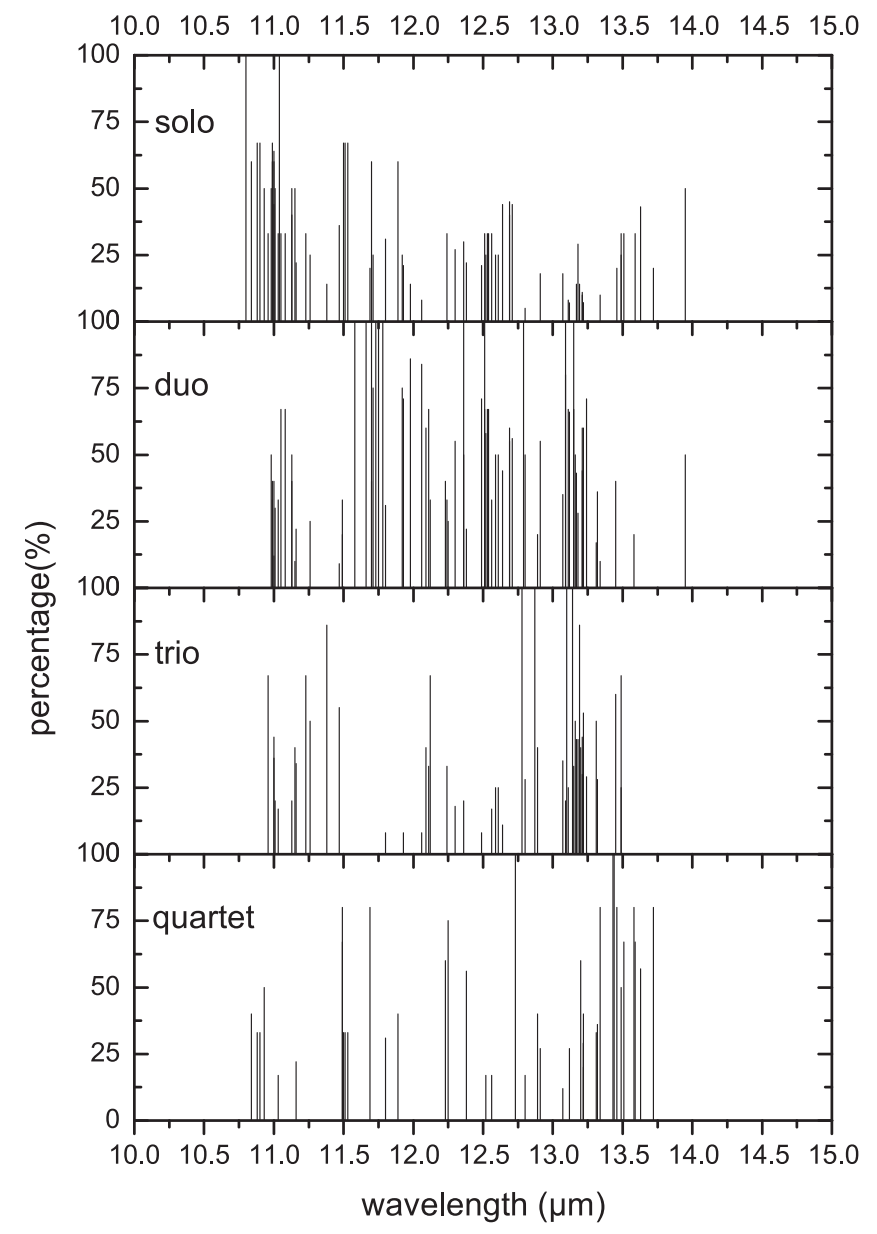

Figure 3. Band positions of the 112 pure OOP modes of the $60 \mathrm{PAH}$ molecules separated into peripheral $\mathrm{H}$ classes (from top to bottom: solo, duo, trio, and quartet). The height of each line corresponds to the percentage of each class.

mode. The percentage of solo, duo, trio, and quartet sites of each of the $60 \mathrm{PAH}$ molecules in our sample (including both uniform and non-uniform edge species) is given in Table 1.

Out of the 227 vibrational bands in the $10.8-15 \mu \mathrm{m}$ region, there are 112 bands that are found to be pure OOP vibrational modes, the other 115 bands are ring- $\mathrm{C}-\mathrm{H}$ coupled OOP vibrations. Excluding the coupled OOP bands our vibrational analysis shows that all classes of $\mathrm{H}$ atoms could have a significant contribution to the pure OOP bands, covering the entire wavelength range of $10.8-15 \mu \mathrm{m}$. Figure 3 plots the wavelength positions of each of the 112 pure OOP bands, separated into solo, duo, trio, and quartet classes (shown in four separate panels). From the heights and concentrations of the lines, we can see that the solo bands are mostly clustered around $11.0 \mu \mathrm{m}$, although they can extend as far as $14 \mu \mathrm{m}$. The duo modes are more evenly spread, with concentrations in particular around $11.8 \mu \mathrm{m}$, although there are also bands around 12.5 and $13.4 \mu \mathrm{m}$. The trio bands are mostly concentrated around $13.2 \mu \mathrm{m}$. The quattro modes are mostly concentrated around $13.5 \mu \mathrm{m}$ but can be seen at as short as $11 \mu \mathrm{m}$.

These results do not rule out the apparent connection between the OOP frequencies and the number and kind of peripheral $\mathrm{C}-\mathrm{H}$ bonds. They show that correlation is not simple among different kinds of PAH molecule with different exposed edges. It is also not simple if the number of exposed edges of one PAH decreases by a substituent. 


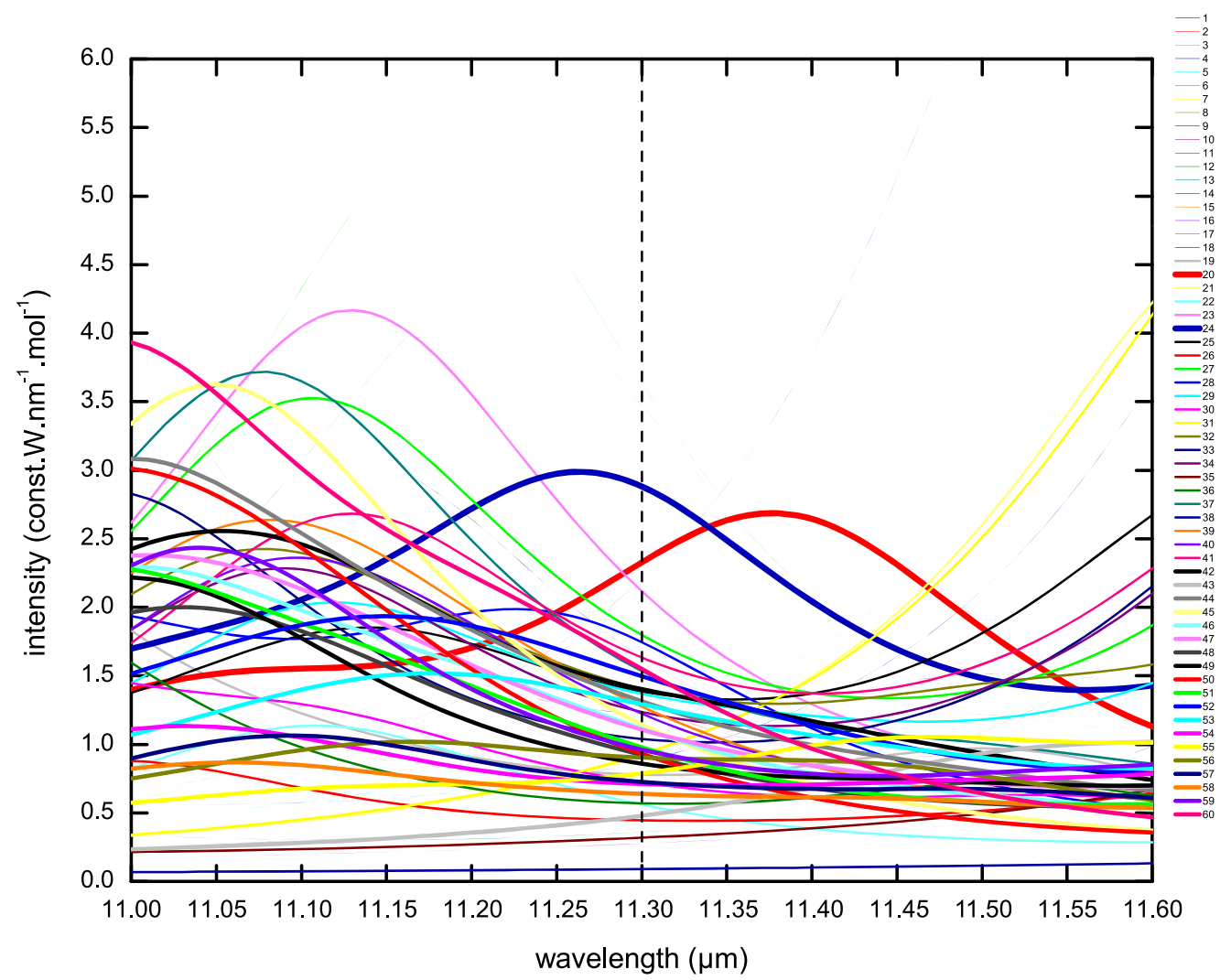

Figure 4. Positions and profiles of the OOP bending modes of $60 \mathrm{PAH}$ molecules. The vertical dashed line represents the nominal peak position of the $11.3 \mu \mathrm{m}$ feature.

In our previous study (Sadjadi et al. 2015) on numbers of substituted ovalene structures, we have shown that the two OOP bands of core PAH at 11.11 and $11.78 \mu \mathrm{m}$ do show the shifts when the number of edge $\mathrm{C}-\mathrm{H}$ group decreases. However, the bands are shifted in different ways. The $11.11 \mu \mathrm{m}$ blueshifted to $10.98 \mu \mathrm{m}$ not just because of the change in the number of exposed edges on the ring but because of the coupling to vibrational modes of aliphatic groups. At the same time, the other strong OOP band at $11.78 \mu \mathrm{m}$ is redshifted instead of blueshifted when the number of exposed edges is decreased.

\subsection{PAH Molecules as the Carrier of the $11.3 \mu \mathrm{m}$ Feature}

Since the OOP vibrational frequencies of PAH molecules can be calculated precisely, how well do they fit the astronomical $11.3 \mu \mathrm{m}$ feature? Our sample in Table 1 contains 60 neutral PAH molecules containing 6-80 C atoms of different honeycomb structures. We have calculated the OOP bending mode frequencies of the PAH molecules. The simulated emission spectra of these molecules in the wavelength range of $11-11.6 \mu \mathrm{m}$ are plotted in Figure 4 . We note that no band peaks are observed at the position of $11.30 \mu \mathrm{m}$ among this set of PAH molecules. Only two molecules in the sample, bisanthene $\left(\mathrm{C}_{28} \mathrm{H}_{14}\right)$ and Dibenzo[bc, ef]coronene $\left(\mathrm{C}_{30} \mathrm{H}_{14}\right)$, exhibit a band close to $11.3 \mu \mathrm{m}$, at 11.38 and $11.26 \mu \mathrm{m}$, respectively.

Although 60 is not a large number, our results suggest that the OOP bending modes of neutral PAH molecules, even including PAH molecules of different geometry with solo, duo, trio, etc., sites, are unlikely to be able explain the observed astronomical $11.3 \mu \mathrm{m}$ feature. In the literature, support for the
PAH hypothesis has cited the success in fitting the astronomical spectra using a mixture of PAH molecules with different sizes, geometry, and charged states. In the next section, we will explore in detail how well such fittings perform in fitting actual astronomical spectra.

\section{FITTING OF THE $11.3 \mu \mathrm{M}$ FEATURE BY THE PAH MODEL}

We performed spectral fitting of the observed $11.3 \mu \mathrm{m}$ feature in five astronomical objects using the PAHdb and the IDL package AmesPAHdbIDLSuite developed by Boersma et al. (2014). ${ }^{2}$ Two of the objects are planetary nebulae, one is a reflection nebula, one is a post-AGB star, and one is an active galaxy. The astronomical spectra were downloaded from the Spitzer Heritage Archive and the Infrared Space Observatory (ISO) Archive. We have subtracted the continuum using a linear fit to the line-free regions. Details of the fitting procedure can be found in Boersma et al. (2013, see their Section 3). Note that Boersma et al. (2013) include only pure and nitrogencontaining PAHs. In this study, all theoretical spectra contained in Version 2.00 of the PAHdb, including pure PAHs and heteroatom molecules, was taken into account in the fitting. For the spectral fittings, we have employed the thermal approximation for all the species, in which the theoretical intensities were scaled by a Planck function at $500 \mathrm{~K}$. A Lorentzian profile with a bandwidth of $15 \mathrm{~cm}^{-1}$ was assumed.

The fitting results are shown in Figures 5-9. The five molecular species that contribute the most to the fitting of the feature are displayed in each of the figures. In all of these

http://www.astrochem.org/pahdb 


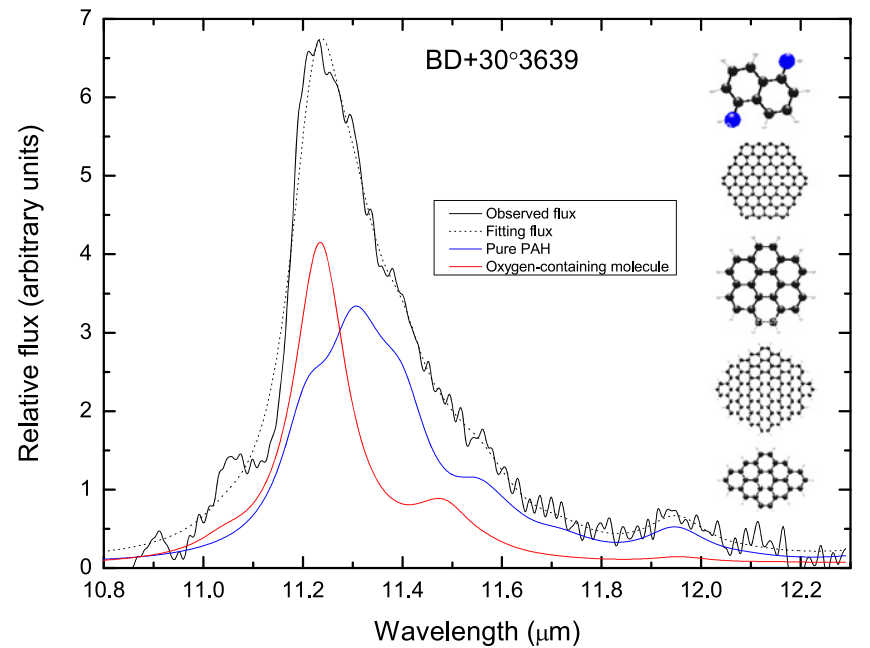

Figure 5. Fittings of the $11.3 \mu \mathrm{m}$ UIE feature in the planetary nebula $\mathrm{BD}+30^{\circ}$ 3639 using the PAHdb model. The black solid line is the continuum-subtracted ISO spectrum and the black dotted line is the model fit by the PAHdb. The blue line represents the total contributions from all of the PAH ions and molecules, and the red line represents the contribution from oxygen-containing species. The chemical structures of the major contributors are given on the right side of the figure (from top to bottom: $\mathrm{C}_{10} \mathrm{H}_{8} \mathrm{O}_{2}, \mathrm{C}_{96}^{+2}, \mathrm{C}_{24} \mathrm{H}_{12}^{+2}, \mathrm{C}_{102} \mathrm{H}_{26}$, and $\mathrm{C}_{30} \mathrm{H}_{14}$ ). The $\mathrm{C}$ atoms are shown as black circles, $\mathrm{H}$ as small gray dots, and $\mathrm{O}$ atoms as blue circles.

examples, O-containing species (in particular, dihydroynaphthalene $\mathrm{C}_{10} \mathrm{H}_{8} \mathrm{O}_{2}$ ) is a major contributor to the $11.3 \mu \mathrm{m}$ feature. In some cases, its contribution is even larger than the total contribution from pure PAHs. Given the fact that the PAHdb contains hundreds of PAH molecules, it is surprising that $\mathrm{O}$-containing (and sometimes $\mathrm{Mg}$ - and Fe-containing) molecules are needed to fit the $11.3 \mu \mathrm{m}$ feature.

From our fittings, O-containing molecules contribute $42 \%$, $44 \%, 14 \%, 54 \%$, and $45 \%$ of the total flux of the $11.3 \mu \mathrm{m}$ feature in $\mathrm{BD}+30^{\circ} 3639$, NGC 7027, NGC 7023, M82, and HD 44179, respectively. In principle, the fitting results can be used to estimate the abundance ratio of carbon locked in the O-containing molecules and pure PAHs if their UV absorption cross-sections are known. The calculation method is detailed in Tielens (2005) and has been applied to derive the abundances of $\mathrm{C}_{60}$ and PAHs (Berné \& Tielens 2012). However, to our knowledge, there is no reported measurement on the UV absorption cross-section of $\mathrm{C}_{10} \mathrm{H}_{8} \mathrm{O}_{2}$. Adopting the same value as for PAH molecules $\left(7 \times 10^{-18} \mathrm{~cm}^{2}\right.$ per $\mathrm{C}$ atom), we assume that the fraction of carbon locked in $\mathrm{C}_{10} \mathrm{H}_{8} \mathrm{O}_{2}$ and PAHs $(f)$ is approximately equal to the ratio of their contributions to the flux of the $11.3 \mu \mathrm{m}$ feature. Using the median value of the flux contribution from O-containing species $(44 \%)$, we have a rough estimate of $f=0.8$, suggesting an $\mathrm{O} / \mathrm{C}$ ratio of about 0.1 .

We note that the $\mathrm{Mg}^{2+}$ and $\mathrm{Fe}^{2+}$ containing molecules are similar complexes where the $\mathrm{PAH}$ is acting as $\pi$ electron donor to the metal atoms. Also, the molecules are selected by PAHdb to achieve a good fit and they are not necessarily physically viable molecules. For example, $\mathrm{C}_{54}$ (used to fit the Red Rectangle) and $\mathrm{C}_{96}^{+}$(used to fit M82) have very high number of dangling bonds and should be extremely reactive. It is unrealistic to expect molecules of very short lifetimes to play a role in the formation of the astronomical $11.3 \mu \mathrm{m}$ feature in the interstellar medium.

Since the code automatically selects spectra from the data pool to get the best fitting and the data pool contains many

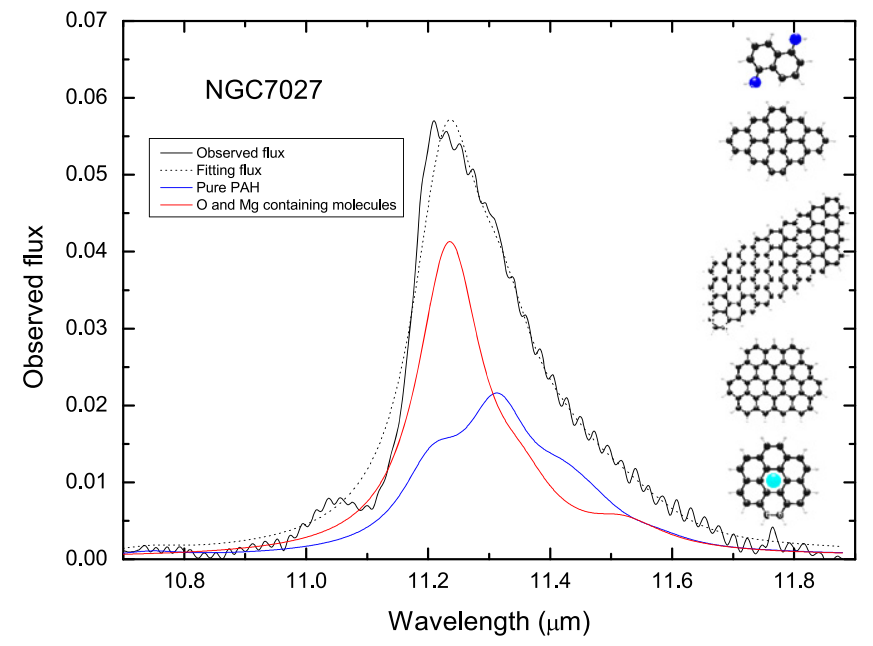

Figure 6. Fittings of the $11.3 \mu \mathrm{m}$ UIE feature in the planetary nebula NGC 7027 using the PAHdb model. The black solid line is the continuum-subtracted ISO spectrum and the black dotted line is the model fit by the PAHdb. The blue line represents the total contributions from all of the PAH ions and molecules, and the red line represents the contribution from oxygen- and magnesiumcontaining species. The chemical structures of the major contributors are given on the right side of the figure (from top to bottom: $\mathrm{C}_{10} \mathrm{H}_{8} \mathrm{O}_{2}, \mathrm{C}_{48} \mathrm{H}_{18}, \mathrm{C}_{98} \mathrm{H}_{28}^{+}$, $\mathrm{C}_{47} \mathrm{H}_{17}$, and $\mathrm{C}_{24} \mathrm{H}_{12} \mathrm{Mg}^{+2}$ ). The $\mathrm{C}$ atoms are shown as black circles, $\mathrm{H}$ as small gray dots, and $\mathrm{O}$ and $\mathrm{Mg}$ atoms as dark and light blue circles, respectively.

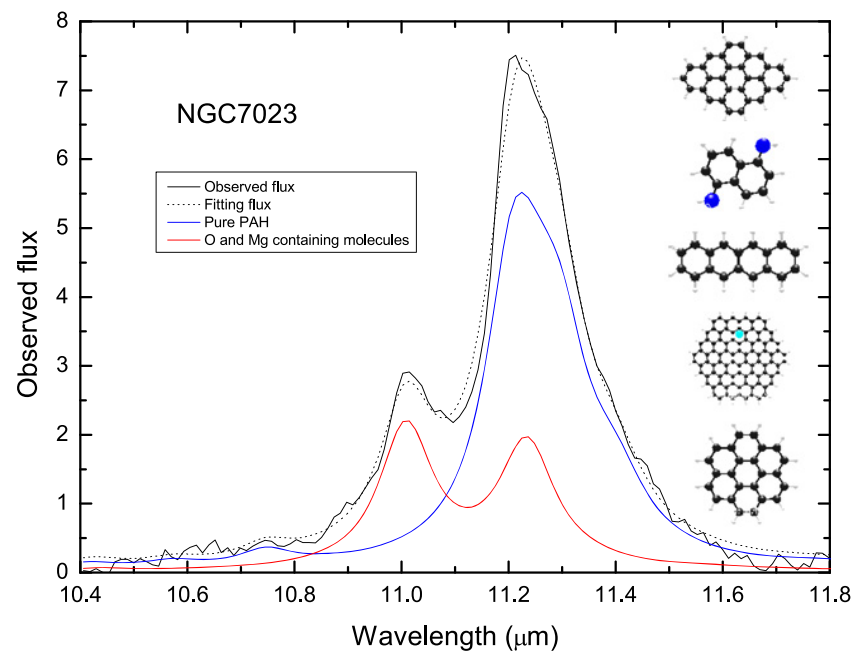

Figure 7. Fittings of the $11.3 \mu \mathrm{m}$ UIE feature in the reflection nebula NGC 7023 using the PAHdb model. The black solid line is the continuum-subtracted Spitzer IRS spectrum and the black dotted line is the model fit by the PAHdb. The blue line represents the total contributions from all of the PAH ions and molecules, and the red line represents the contribution from oxygen- and magnesium-containing species. The chemical structures of the major contributors are given on the right side of the figure (from top to bottom: $\mathrm{C}_{48} \mathrm{H}_{18}, \mathrm{C}_{10} \mathrm{H}_{8} \mathrm{O}_{2}, \mathrm{C}_{18} \mathrm{H}_{12}, \mathrm{C}_{96} \mathrm{H}_{24} \mathrm{Mg}^{+}$, and $\left.\mathrm{C}_{32} \mathrm{H}_{14}^{+2}\right)$. The $\mathrm{C}$ atoms are shown as black circles, $\mathrm{H}$ as small gray dots, and $\mathrm{O}$ and $\mathrm{Mg}$ atoms as dark and light blue circles, respectively.

hundreds of pure PAHs and very few heteroatom molecules, we can safely conclude that the inclusion of the O-containing species is needed to achieve a good fit. We can compare these fits with the fits to NGC 7023 by Boersma et al. (2013). Examination of Figure 4 of Boersma et al. (2013) shows that their model spectrum contains features on the shoulders of the $11.3 \mu \mathrm{m}$ feature, which are not seen in observations. This confirms that the PAHdb model, even with the large number of parameters, has difficulty fitting the feature with pure PAH molecules and ions. 


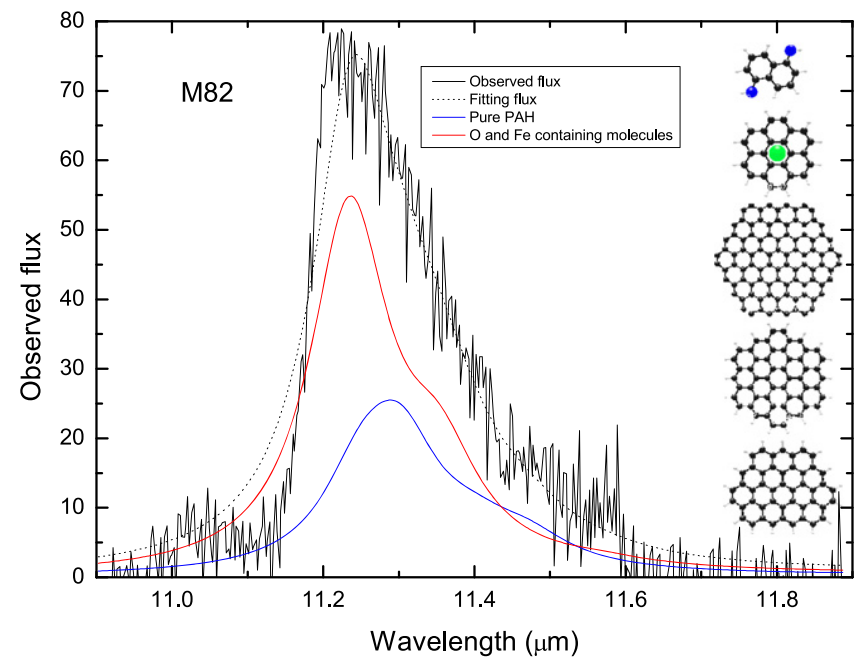

Figure 8. Fittings of the $11.3 \mu \mathrm{m}$ UIE feature in the active galaxy M82 using the PAHdb model. The black solid line is the continuum-subtracted ISO spectrum and the black dotted line is the model fit by the PAHdb. The blue line represents the total contributions from all of the PAH ions and molecules, and the red line represents the contribution from oxygen- and magnesiaumcontaining species. The chemical structures of the major contributors are given on the right side of the figure (from top to bottom: $\mathrm{C}_{10} \mathrm{H}_{8} \mathrm{O}_{2}, \mathrm{C}_{24} \mathrm{H}_{12} \mathrm{Fe}^{+2}, \mathrm{C}_{96}^{+2}$, $\mathrm{C}_{54} \mathrm{H}_{18}$, and $\mathrm{C}_{47} \mathrm{H}_{17}$ ). The $\mathrm{C}$ atoms are shown as black circles, $\mathrm{H}$ as small gray dots, $\mathrm{O}$ as dark, and $\mathrm{Fe}$ as green circles.

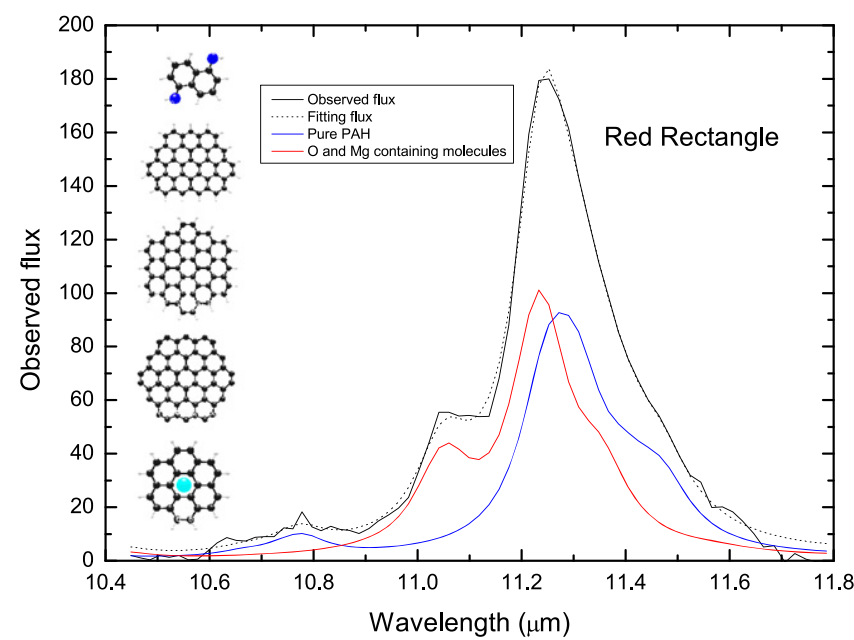

Figure 9. Fittings of the $11.3 \mu \mathrm{m}$ UIE feature in the reflection nebula HD 44179 using the PAHdb model. The black solid line is the continuumsubtracted ISO spectrum and the black dotted line is the model fit by the PAHdb. The blue line represents the total contributions from all of the PAH ions and molecules, and the red line represents the contribution from oxygenand magnesiaum-containing species. The chemical structures of the major contributors are given on the right side of the figure (from top to bottom: $\mathrm{C}_{10} \mathrm{H}_{8} \mathrm{O}_{2}, \mathrm{C}_{47} \mathrm{H}_{17}, \mathrm{C}_{54} \mathrm{H}_{18}, \mathrm{C}_{54}$, and $\mathrm{C}_{24} \mathrm{H}_{12} \mathrm{Mg}^{+2}$ ). The $\mathrm{C}$ atoms are shown as black circles, $\mathrm{H}$ as small gray dots, and $\mathrm{O}$ and $\mathrm{Mg}$ atoms as dark and light blue circles, respectively.

\section{DISCUSSIONS}

A successful model for the carrier of the UIE phenomenon has to produce strong consistent features at 3.3, 6.2, 7.7, 8.6, and $11.3 \mu \mathrm{m}$, accompanied by broad plateau features around 8 and $12 \mu \mathrm{m}$, and have no strong narrow features in between the strong UIE bands. The difficulty in PAH molecules meeting these criteria has been discussed by Cook \& Saykally (1998). The way to get around these problems in the past is to invoke a large mix of PAH molecules of different masses, sizes, geometry and ionized states and fit the astronomical spectra by adjusting the relative abundance of hundreds of molecular species. Anharmonic shifts and hot bands are also included to improve the fits (Pech et al. 2002). By introducing an emission model that includes a mass distribution of PAH molecules, temperature-dependent linewidths, and the spectral energy distribution of the background radiation source, Candian \& Sarre (2015) are able to fit the observed profiles of the $11.3 \mu \mathrm{m}$ feature. For example, the asymmetric profile of the feature is reproduced by having different mass components. Recent work has expanded the PAH database to incorporate dehydrogenated PAH molecules, including those with non-planar structures (Mackie et al. 2015). Another possibility is to include protonated PAHs. However, recent experimental IR spectra suggest that neither neutral-protonated (H.PAH) or cationicprotonated $\left(\mathrm{H}^{+} \mathrm{PAH}\right)$ forms could successfully produce the $11.3 \mu \mathrm{m}$ feature in moderate-size PAHs such as coronene (Bahou et al. 2014). Since astronomical UIE spectra are observed in very different radiation environments, it would not be reasonable to assume that the PAH population will consist of PAH molecules of the same mix of physical (ionization, dehydrogenation, protonation) states and mass distributions everywhere. The large number of free parameters used in these fits also raises doubts about their validity as practically any spectra can be fitted by such methods (Zhang \& Kwok 2015).

If PAH molecules are not the carriers of the $11.3 \mu \mathrm{m}$ feature, what are the other possible candidates? Amorphous carbonaceous solids are also known to possess infrared vibrational based similar to the UIE bands (Dischler et al. 1983a, 1983b; Guillois et al. 1996). Figure 10 shows a comparison between the astronomical UIE spectrum with the laboratory spectrum of nanoparticles produced by laser pyrolysis of hydrocarbons (Herlin et al. 1998). The laboratory spectrum of these particles show general resemblance to the astronomical spectrum, not only in the major UIE bands, but also in the plateau features. The features are naturally broad and do not need to be artificially broadened as in gas-phase molecules. In addition to the $11.3 \mu \mathrm{m}$ feature, strong peaks are seen at 11.9 and $13.3 \mu \mathrm{m}$.

In order to examine the infrared activity of hydrocarbons with mixed aromatic/aliphatic structures, we have calculated the simulated infrared spectra (Figure 11) for 13 different examples of such structures (Figure 12). For simplicity, we have only explored molecules that consist of single aromatic rings and aliphatic chains consisting of methyl and methylene groups. As such, they represent a simple subset of MAONs (Kwok \& Zhang 2011). The number of free hydrogen atoms on all benzene rings (the numbers inside the bracket in Figure 11) is kept the same in each structure. We also include an example of a pure aliphatic molecule $\left(\mathrm{C}_{50} \mathrm{H}_{102}\right)$ for comparison.

The first notable difference between these molecules and PAH molecules is in the way that the infrared bands appear at different parts of spectra as the size of molecules increases. The infrared bands of PAH molecules with different sizes can appear in every part of the spectra as each vibrational mode has significant variations in peak wavelengths. The MAON-like spectra, however, have vibrational modes occurring at consistent wavelengths and are not highly dependent on the size of the molecules (Figure 11). The six main features around $3.4,6.2-6.4,6.9-7.4,9-12,12-15$, and $15-20 \mu \mathrm{m}$ can roughly be identified as aliphatic $\mathrm{C}-\mathrm{H}$ stretching, aromatic $\mathrm{C}=\mathrm{C}$ stretching, scissors mode of methylene $\mathrm{C}-\mathrm{H}$ bonds coupled with the umbrella deformation mode of methyl $\mathrm{C}-\mathrm{H}$ bonds, 

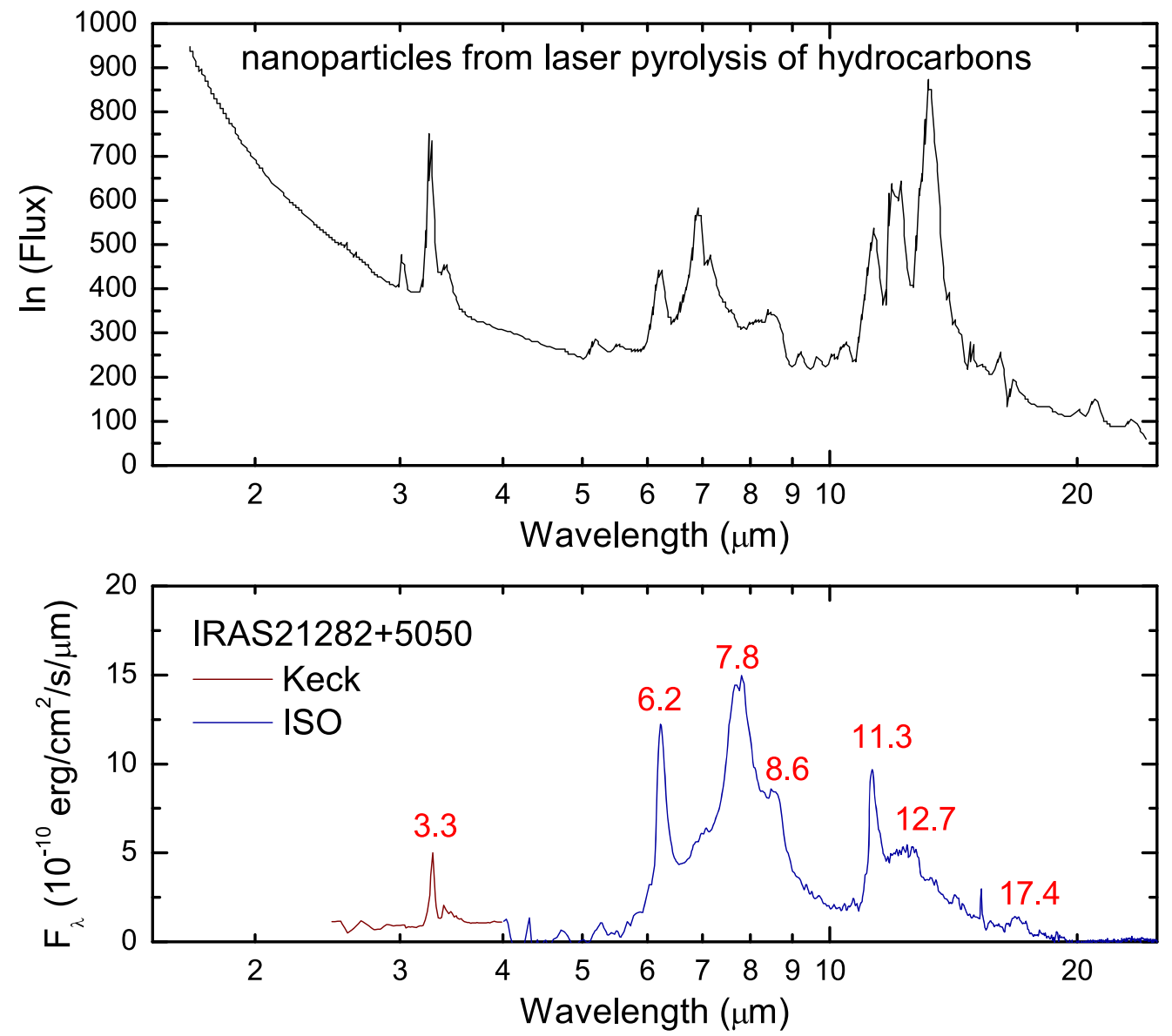

Figure 10. Comparison of the laboratory spectrum of nanoparticles produced by laser pyrolysis of hydrocarbons (Herlin et al. 1998; top panel) with the astronomical spectrum of the planetary nebula IRAS $21282+5050$ (bottom panel). The peak wavelengths (in units of $\mu \mathrm{m}$ ) of the astronomical UIE bands are marked in red. The long-wavelength $(>4 \mu \mathrm{m})$ part of the spectrum of IRAS $21282+5050$ is from ISO and the short wavelength $(<4 \mu \mathrm{m})$ are from ground-based observations $($ Hrivnak et al. 2007).

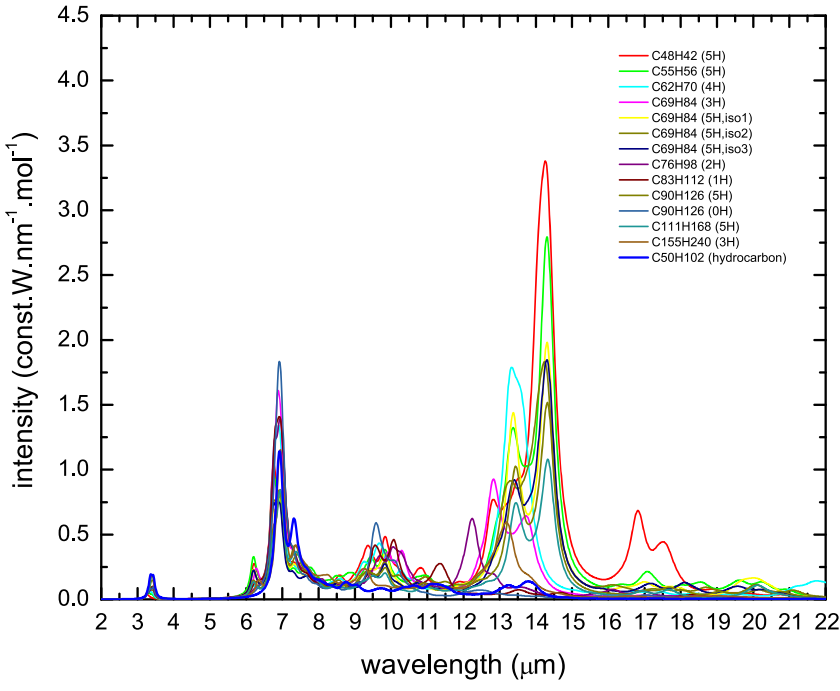

Figure 11. Infrared spectra of 13 simple MAON-like molecules. In spite of the different sizes of the molecules, the vibrational modes seem to cluster around consistent frequencies. The spectrum of the pure aliphatic molecule $\mathrm{C}_{50} \mathrm{H}_{102}$ is also plotted for comparison. methyl and methylene deformation modes coupled with aromatic $\mathrm{C}-\mathrm{H}$ in-plane bending modes, aromatic $\mathrm{C}-\mathrm{H}$ OOP, and aliphatic fragment group frequencies coupled with aromatic ring-OOP deformation modes. However as discussed by Sadjadi et al. (2015), all of these modes have a varying degree of coupling between aromatic and aliphatic components. The six peaks in Figure 11 show some qualitative resemblance to the astronomical UIE spectra (lower panel, Figure 10), although there is not an exact correspondence in peak wavelengths. For example, the OOP bending modes of these 14 molecules range from 12 to $15 \mu \mathrm{m}$, approximately resembling the $12 \mu \mathrm{m}$ emission plateau feature but without showing a definite peak at $11.3 \mu \mathrm{m}$. Further theoretical investigation of the vibrational modes of MAON structures with larger sizes and complexity is needed.

\section{CONCLUSIONS}

The UIE bands are commonly found throughout the universe and the energy emitted from these bands represents a significant output of active galaxies. Since the strengths of UIE bands and their distributions are used as a diagnostic tool 


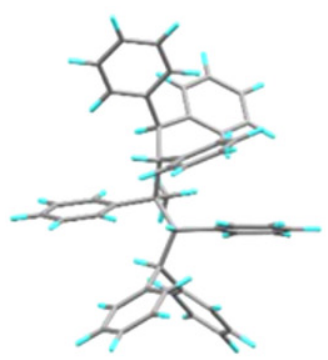

$\mathrm{C}_{48} \mathrm{H}_{42}(5 \mathrm{H})$

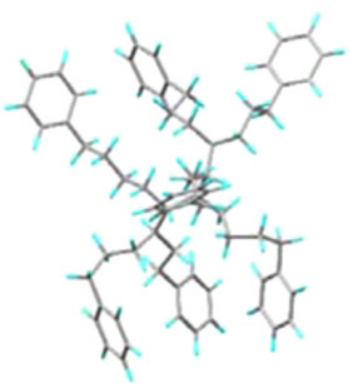

$\mathrm{C}_{69} \mathrm{H}_{84}(5 \mathrm{H}$, iso 1$)$

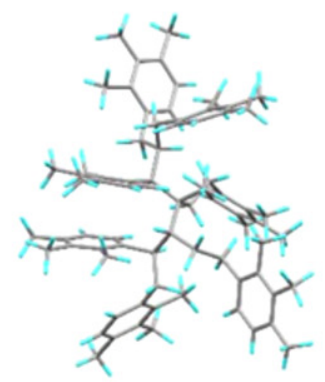

$\mathrm{C}_{76} \mathrm{H}_{98}(2 \mathrm{H})$

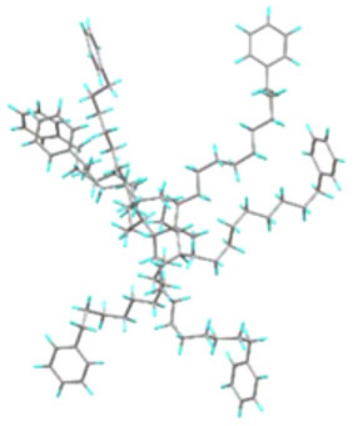

$\mathrm{C}_{111} \mathrm{H}_{168}(5 \mathrm{H})$

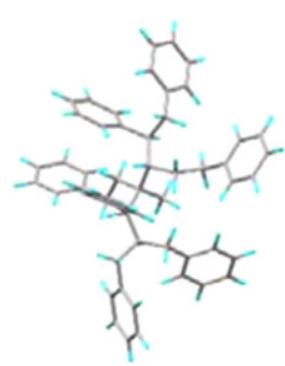

$\mathrm{C}_{55} \mathrm{H}_{56}(5 \mathrm{H})$

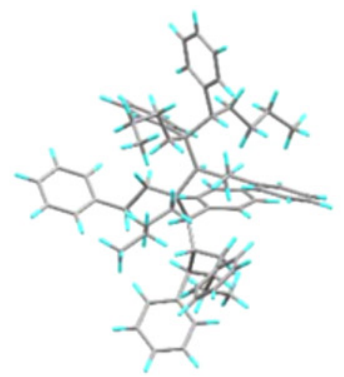

$\mathrm{C}_{69} \mathrm{H}_{84}(5 \mathrm{H}$, iso2 $)$

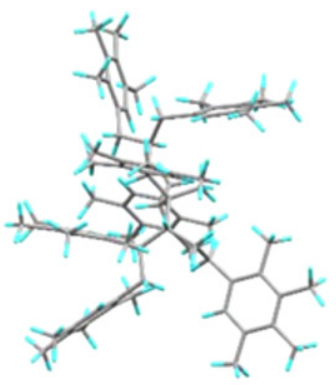

$\mathrm{C}_{83} \mathrm{H}_{112}(1 \mathrm{H})$

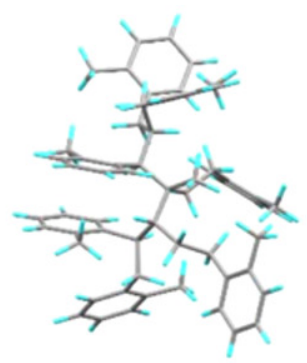

$\mathrm{C}_{62} \mathrm{H}_{70}(4 \mathrm{H})$

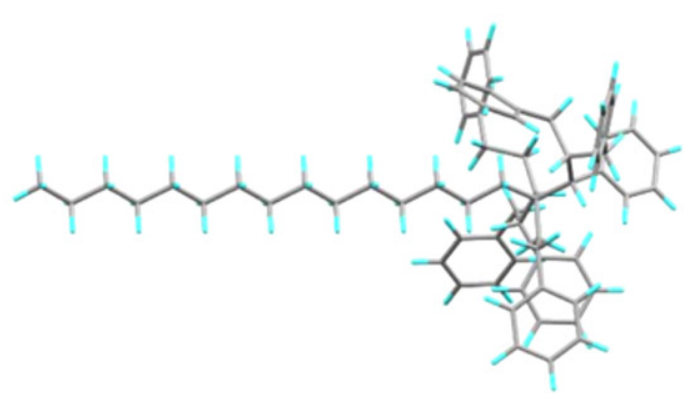

$\mathrm{C}_{69} \mathrm{H}_{84}(5 \mathrm{H}$, iso3 $)$

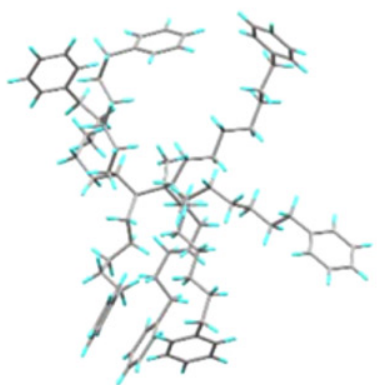

$\mathrm{C}_{90} \mathrm{H}_{126}(5 \mathrm{H})$

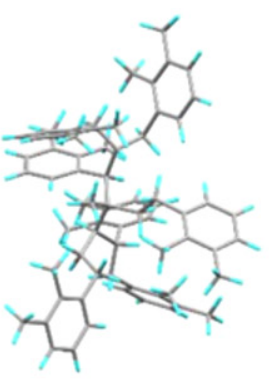

$\mathrm{C}_{69} \mathrm{H}_{84}(3 \mathrm{H})$

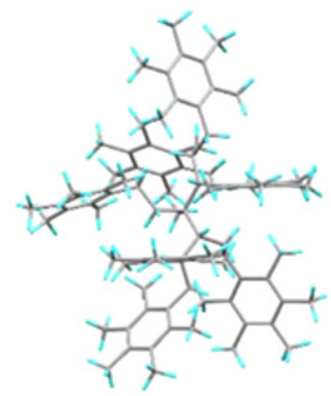

$\mathrm{C}_{90} \mathrm{H}_{126}(\mathrm{OH})$

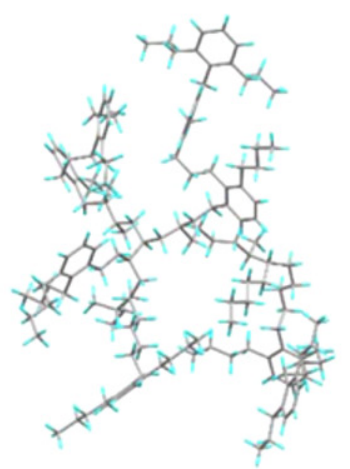

$\mathrm{C}_{155} \mathrm{H}_{240}(3 \mathrm{H})$

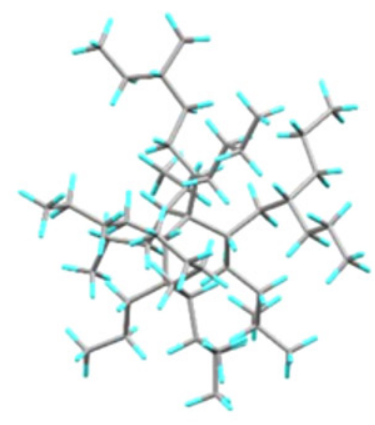

$\mathrm{C}_{50} \mathrm{H}_{102}$ (hydrocarbon)

Figure 12. Chemical structures of the 14 molecules used in Figure 11. All of the aromatic rings in each of the molecules have the same number of $\mathrm{H}$ atoms not substituted by methyl and methylene groups (the number inside the brackets). One molecule $\left(\mathrm{C}_{50} \mathrm{H}_{102}\right)$ has no aromatic rings. The labels iso1, iso2, and iso3 refer to three different isomers of the molecule $\mathrm{C}_{69} \mathrm{H}_{84}$. 
of the physical and radiative environment of galactic and extragalactic objects, a correct identification of its origin is of utmost importance. Whether it originates from gas-phase molecules or complex organic solids can also alter our view of the chemical abundance of interstellar matter.

The astronomical UIE bands have consistent patterns in different astronomical environments and such consistency is difficult to explain by simple, gas-phase PAH molecules. The $11.3 \mu \mathrm{m}$ UIE feature cannot be fitted by superpositions of hundreds of pure PAH molecules, even including PAH molecules of different sizes and charged states. In order to correctly identify the origin of the UIE bands, we need to explore more complex structures, specifically those with mixed aromatic/aliphatic structures. Preliminary results in this paper show that the MAON-like structures have consistent clusters of vibrational bands and therefore are viable candidates for the carrier of the astronomical UIE bands.

We dedicate this paper to our friend and colleague Tom Ziegler who passed away in 2015. Tom was a pioneer in the development of the DTF method, which makes possible the calculations performed in this paper. We thank Franco Cataldo and Renaud Papoular for helpful comments on an earlier draft of this manuscript. The fitting models were done using the NASA Ames Research Center PAH IR Spectroscopic Database and software and we thank Christiaan Boersma for making these resources publicly available. This work was partially supported by the Research Grants Council of the Hong Kong Special Administrative Region, China (project No. 17302214).

\section{REFERENCES}

Allamandola, L. J., Tielens, A. G. G. M., \& Barker, J. R. 1985, ApJL, 290, L25 Bahou, M., Wu, Y.-J., \& Lee, Y.-P. 2014, Angew. Chem. Int. Ed. 2014, 53, 1021

Balm, S. P., \& Kroto, H. W. 1990, MNRAS, 245, 193

Barlow, M. J. 1983, in IAU Symp. 103, Planetary Nebulae, ed. D. R. Flower (Dordrecht: Kluwer), 105

Bauschlicher, C. W., Jr., Boersma, C., Ricca, A., et al. 2010, ApJS, 189, 341 Becke, A. D. 1993a, JChPh, 98, 5648

Becke, A. D. 1993b, JChPh, 98, 1372

Bellamy, L. J. 1958, The Infra-red Spectra of Complex Molecules (2nd ed; London: Methuen)

Berné, O., \& Tielens, A. G. G. M. 2012, PNAS, 109, 401

Bernstein, L. S., \& Lynch, D. K. 2009, ApJ, 704, 226

Boersma, C., Bauschlicher, C. W., Jr., Ricca, A., et al. 2014, ApJS, 211, 8

Boersma, C., Bregman, J. D., \& Allamandola, L. J. 2013, ApJ, 769, 117

Borghesi, A., Bussoletti, E., \& Colangeli, L. 1987, ApJ, 314, 422

Bregman, J. D., Allamandola, L. J., Witteborn, F. C., Tielens, A. G. G. M., \& Geballe, T. R. 1989, ApJ, 344, 791

Bregman, J. D., Hayward, T. L., \& Sloan, G. C. 2000, ApJL, 544, L75
Candian, A., \& Sarre, P. J. 2015, MNRAS, 448, 2960

Cataldo, F., García-Hernández, D. A., \& Manchado, A. 2013, MNRAS, 429, 3025

Cataldo, F., \& Keheyan, Y. 2003, IJAsB, 2, 41

Cohen, M., Tielens, A. G. G. M., \& Allamandola, L. J. 1985, ApJL, 299, L93

Cook, D. J., \& Saykally, R. J. 1998, ApJ, 493, 793

Dischler, B., Bubenzer, A., \& Koidl, P. 1983a, SSCom, 48, 105

Dischler, B., Bubenzer, A., \& Koidl, P. 1983b, ApPhL, 42, 636

Duley, W. W., \& Williams, D. A. 1981, MNRAS, 196, 269

Duley, W. W., \& Williams, D. A. 1983, MNRAS, 205, 67

Frisch, M. J., Frisch, G. W., Trucks, H. B., et al. 2009, Gaussian 09, Revision C.01, Gaussian, Inc., Wallingf

Galliano, F., Madden, S. C., Tielens, A. G. G. M., Peeters, E., \& Jones, A. P. 2008, ApJ, 679, 310

Gillett, F. C., Forrest, W. J., \& Merrill, K. M. 1973, ApJ, 183, 87

Goebel, J. H., Cheeseman, P., \& Gerbault, F. 1995, ApJ, 449, 246

Guillois, O., Nenner, I., Papoular, R., \& Reynaud, C. 1996, ApJ, 464, 810

Herlin, N., Bohn, I., Reynaud, C., et al. 1998, A\&A, 330, 1127

Hertwig, R. H., \& Koch, W. 1997, CPL, 268, 345

Hrivnak, B. J., Geballe, T. R., \& Kwok, S. 2007, ApJ, 662, 1059

Hony, S., van Kerckhoven, C., Peeters, E., et al. 2001, A\&A, 370, 1030

Hudgins, D. M., \& Allamandola, L. J. 1999, ApJL, 516, L41

Jensen, F. 2001, JChPh, 115, 9113

Jensen, F. 2002, JChPh, 116, 7372

Joblin, C., \& Tielens, A. G. G. M. 2011, in EAS Publications Ser., vol. 46, A Symposium to Celebrate the 25th Anniversary of the PAH Hypothesis, ed. C. Joblin \& A. G. G. M. Tielens (Les Ulis: EDP Sciences)

Justtanont, K., Barlow, M. J., Skinner, C. J., et al. 1996, A\&A, 309, 612

Keller, L. D., Sloan, G. C., Forrest, W. J., et al. 2008, ApJ, 684, 411

Kwok, S., Volk, K., \& Bernath, P. 2001, ApJL, 554, L87

Kwok, S., Volk, K., \& Hrivnak, B. J. 1999, A\&A, 350, L35

Kwok, S., \& Zhang, Y. 2011, Natur, 479, 80

Kwok, S., \& Zhang, Y. 2013, ApJ, 771, 5

Laury, M. L., Carlson, M. J., \& Wilson, A. K. 2012, JCoCh, 33, 2380

Léger, A., \& Puget, J. L. 1984, A\&A, 137, L5

Mackie, C. J., Peeters, E., Bauschlicher, C. W., Jr., \& Cami, J. 2015, ApJ, 799, 131

Malloci, G., Joblin, C., \& Mulas, G. 2007, CP, 332, 353

Matsuura, M., Bernard-Salas, J., Lloyd Evans, T., et al. 2014, MNRAS, 439, 1472

Papoular, R., Conrad, J., Giuliano, M., Kister, J., \& Mille, G. 1989, A\&A, 217, 204

Pech, C., Joblin, C., \& Boissel, P. 2002, A\&A, 388, 639

Peeters, E., Hony, S., Van Kerckhoven, C., et al. 2002, A\&A, 390, 1089

Peeters, E. 2014, in IAU Symp. 297, The Diffuse Interstellar Bands, ed. J. Cami \& N. L. J. Cox (Cambridge: Cambridge Univ. Press), 187

Puget, J. L., \& Léger, A. 1989, ARA\&A, 27, 161

Russell, R. W., Soifer, B. T., \& Merrill, K. M. 1977a, ApJ, 213, 66

Russell, R. W., Soifer, B. T., \& Willner, S. P. 1977b, ApJL, 217, L149

Sadjadi, S., Zhang, Y., \& Kwok, S. 2015, ApJ, 801, 34

Sakata, A., Wada, S., Onaka, T., \& Tokunaga, A. T. 1987, ApJL, 320, L63

Smith, J. D. T., Draine, B. T., Dale, D. A., et al. 2007, ApJ, 656, 770

Tielens, A. G. G. M. 2005, The Physics and Chemistry of the Interstellar Medium (Cambridge: Cambridge Univ. Press)

van Diedenhoven, B., Peeters, E., van Kerckhoven, C., et al. 2004, ApJ, 611,928

Wu, Y., Helou, G., Armus, L., et al. 2010, ApJ, 723, 895

Zhang, Y., \& Kwok, S. 2015, ApJ, 798, 37 